\title{
Numerical modelling of seepage beneath skirted foundations subjected to
}

\author{
vertical uplift
}

\author{
Divya S. K. Mana ${ }^{1}$, Susan Gourvenec ${ }^{1, *}$ and Mark F. Randolph ${ }^{1}$
}

\begin{abstract}
This study reports the results of small strain finite element analyses undertaken to determine the rate of displacement of skirted foundations subjected to uplift loading, due to combined swelling and seepage. Compatibility of foundation movement with cumulative seepage of water into the skirt compartment is modelled using a layer of soft poroelastic material immediately below the foundation top plate. Performance of the model is first assessed for a range of stiffness values for the soft layer. The model is then used to investigate the rate of displacement for skirt depths ranging from 0.1 to 1 times the foundation diameter. The results are compared with available theoretical solutions and experimental results, and expressions are provided for calculating the equivalent seepage lengths and resulting uplift velocities. The effect on the seepage behaviour of the presence of a gap down the external skirt-soil interface is also discussed.
\end{abstract}

Keywords: Consolidation; Numerical analysis; Offshore foundations; Seepage; Uplift Words (intro - conclusions inclusive): 4472. Figures: 11. Tables: 1.

${ }^{1}$ Centre for Offshore Foundation Systems, The University of Western Australia, Perth, WA 6009, Australia

* Corresponding author: Email: susan.gourvenec@uwa.edu.au 


\section{Introduction}

Skirted foundations are shallow foundations, which consist of a plate resting on the soil surface and a peripheral skirt (often supplemented by internal skirts) penetrating into the soil. The skirts encapsulate soft soil near the seabed surface, improving the load-carrying capacity of the foundation by forcing the failure deeper, generally into stronger soil. Skirted foundations are widely used for shallow and deep water oil and gas developments, where they may be required to resist uplift loads or significant overturning moments. A sealed skirted foundation resists uplift by generating negative excess pore pressure, often referred to as suction (relative to ambient water pressure), between the underside of the foundation top plate and the confined soil (referred to here as the 'soil plug') within the skirts. The pressure differential sets up seepage flow into and through the soil plug from the surrounding soil and free water at the soil surface. Water accumulates beneath the foundation top plate, allowing the foundation to move upwards at a steady rate, compounded initially by some swelling of the soil within and below the soil plug (see Fig. 1).

Various experimental studies have presented the time-displacement response of skirted foundations and suction caissons (Clukey et al., 2004; Acosta-Martinez et al., 2008; Mana et al., 2012). The studies show that the response is bilinear with the initial portion corresponding to immediate displacement due to the applied load followed by time-dependent displacement due to the flow of water in to the skirt compartment. Some numerical simulations (Zdravkovic et al., 2001; Cao et al., 2002; Deng and Carter, 2002; Al-Khafaji et al., 2003; Clukey et al., 2004) have also considered the uplift load behaviour of skirted foundations and suction caissons. The simulations were mainly used to quantify the pullout capacity of the foundation and negative pore 
pressure development and dissipation underneath the foundation top plate. Seepage and the time-displacement response in uplift of skirted foundations in clay have not previously been studied numerically, although some studies have been reported for skirted foundations in sand (Erbrich and Tjelta, 1999; Houlsby and Byrne, 2005).

Numerical studies have considered the consolidation response of skirted and embedded foundations in clay, under compressive loading, quantifying the displacements and pore pressure dissipation for a range of foundation geometries (Gourvenec and Randolph, 2009, 2010). These studies were based on small strain finite element analysis, with the soil modelled as an isotropic elastic material undergoing Biot-type consolidation. The foundation embedment ratio and skirt-soil interface friction were found to have a significant influence on the consolidation behaviour and hence the foundation settlement.

Seepage flow is only an issue for foundations loaded in uplift. Seepage flow does not occur for skirted foundations loaded in compression, unless free water remains trapped beneath the foundation top plate at the end of installation. Leaving that aside, the soil beneath the foundation undergoes consolidation, excess pore pressures gradually dissipate and the foundation settlement converges towards a long-term value. In uplift, there are three contributions to foundation displacement: an immediate elastic displacement due to the applied load; a time-dependent but transient response to swelling of the soil within and below the skirt compartment; and a steady rate of displacement due to seepage of water into the region beneath the top plate. Provided the uplift load exceeds friction between the skirt wall and the soil, the foundation will continue to move upwards, gradually accelerating due to the decreasing penetration of the skirts within the soil until failure occurs. 
The rate of displacement will increase if there is a gap present between the skirt wall and the surrounding soil, due to the increased proximity of free water to the skirt compartment. Experimental studies of the effect of a gap on the time-displacement response of skirted foundations have indicated large increases in displacement (Acosta-Martinez et al., 2010; Mana et al., 2012).

In this paper, seepage of water into the skirt compartment of shallow skirted foundations subjected to vertical uplift has been modelled using small strain (i.e. without updating of mesh coordinates) finite element analysis. The analyses were performed for an isotropic elastic half space, following Gourvenec and Randolph (2009, 2010), but with a layer of soft poroelastic 'water' elements introduced immediately below the foundation top plate similar to the approach adopted by Cao et al. (2002). The effect of a gap down the external skirt-soil interface was also studied. The results are compared with available theoretical and experimental results for validation of the model.

\section{Finite element modelling}

Small strain finite element analyses were performed using commercial software Abaqus (Dassault Systèmes, 2010). Fig. 2 shows a typical finite element mesh used for this study. The model comprises a rigid skirted foundation, homogeneous isotropic soil and a thin layer of 'water' elements between the underside of the foundation top plate and the confined soil plug.

The water elements were used to ensure uniform negative pore pressure underneath the top plate and to provide compatibility between the foundation displacements and cumulative seepage into the skirt compartment. Previous studies have also considered the presence of a layer of trapped water between the foundation top plate and the soil 
plug in the finite element model, but only to quantify the undrained pullout capacity of the skirted foundations rather than to model seepage. Zdravkovic et al. (2001) used a string of interface elements with very low shear stiffness and very high normal stiffness while Cao et al. (2002) used very soft poroelastic elements to represent the water. An approach similar to the latter has been adopted here, with soft (two-phase) poroelastic elements used to model the accumulating water; a parametric study was performed initially to validate the performance of the elements and to choose an appropriate stiffness.

All the analyses were performed on axisymmetric models, representing the behaviour of circular skirted foundations subjected to pure axial vertical loading.

\section{1. $\quad$ Loading and drainage}

The analyses were performed in two stages: a loading stage and a swelling-seepage stage. In the loading stage, a vertical uplift load was applied to the top plate of the rigid skirted foundation in a single step over a short period of time. During this stage no drainage was allowed and negative excess pore pressures corresponding to the applied pressure were set up around the foundation. After the undrained loading stage, a zero excess pore pressure drainage boundary was specified around the foundation to model the continuous percolation of free water in to the soil, and dissipation of the negative excess pore pressures developed.

Two different drainage boundaries were considered: one with drainage allowed along the top surface of the soil surrounding the foundation; and one with drainage allowed also along the soil outside the skirt wall and below the skirt tip in addition to the top surface of the surrounding soil. The first case represents the drainage behaviour of a foundation with 'intact' skirt-soil interface while the second represents a foundation 
with a 'gap' between the outer surface of the skirt wall and the soil, with free water present in the gap.

The choice of initial time step after loading is an important issue when drainage is considered in a numerical analysis. The time step and element size are related such that immediately after a drainage boundary condition is changed and flow is allowed, sufficient time is permitted for flow through each element. Vermeer and Verruijt (1981) proposed a simple expression to calculate the minimum initial time step $\left(\Delta \mathrm{t}_{\min }\right)$ as a function of the element size and properties of the soil skeleton expressed as,

$$
\Delta \mathrm{t}_{\min } \geq \mathrm{h}^{2} \frac{\gamma_{\mathrm{w}}}{6 \mathrm{Ek}}
$$

where $\mathrm{h}$ is the distance between the nodes of the elements in the region where drainage occurs (in this study, the vertical thickness of the elements adjacent to the skirt was taken), $\gamma_{\mathrm{w}}$ the unit weight of pore water, and E and k respectively Young's modulus of elasticity and the coefficient of permeability of the soil. The same time period was used for the loading step to establish the initial excess pore pressures.

\subsection{Foundation}

Shallow circular skirted foundations with embedment ratios, $d / D$, of $0.1,0.2,0.3,0.5$ and 1 were modelled in the study, where $d$ is the skirt embedment depth and D the (external) base diameter of the foundation. Skirt wall thickness $\left(t_{w}\right)$ equivalent to $t_{w} / D$ $=0.008$ was adopted, similar to the geometry of steel skirted foundations used in the field (e.g. Bye et al., 1995). The foundations were modelled as rigid, solid and impermeable. Installation was not modelled and the foundation was in position at the start of each analysis. 
The interfaces between the inner surface of the skirt compartment and the soil plug and water were assigned smooth, with full bonding in the normal direction. The interface of the skirt tip and the outer skirt wall with the soil was also fully bonded in the normal direction, but allowed to separate under tension (so forcing the normal stress to be non-negative. This was essential to prevent influence of the tension capacity at skirt tip affecting the seepage velocities and to ensure convergence of the numerical simulations due to the presence of water elements. Since the purpose of the study was to examine the rate of foundation displacement during steady seepage of water into the skirt compartment, all interfaces were taken as smooth in shear. This allowed large relative movements to occur, for example between the skirt wall and adjacent soil on either side. The choice of assuming smooth interfaces between skirt and soil was made deliberately in order to provide upper limits to the magnitude of steady-state displacement rates.

All parameters used for the study are summarised in Table 1. While most results are presented in non-dimensional form, the foundation dimensions were chosen to match those used in experimental studies (Mana et al., 2012).

\subsection{Soil}

The modelled soil zone had a radius and depth equal to six times the radius of the foundation, from the centre of the foundation at the bottom side of the top plate (Fig. 2). Roller supports were provided around the circumference and base of the soil. An axis of symmetry for the radial plane was defined along the centreline of the model. No drainage was allowed along the circumferential and base boundaries of soil.

The soil was modelled as an isotropic elastic material with Biot-type three dimensional consolidation (Biot, 1935, 1941) governing the stress-pore fluid coupling. 
The soil was assumed to be fully saturated and weightless. The soil was assigned constant and isotropic values of Young's modulus, E $=5000 \mathrm{kPa}$, Poisson's ratio, $v=0.2$ and coefficient of permeability, $\mathrm{k}=1 \times 10^{-9} \mathrm{~m} / \mathrm{s}$. Unit weight of pore water was assigned as $\gamma_{\mathrm{w}}=10 \mathrm{kN} / \mathrm{m}^{3}$. The coefficient of consolidation $\left(\mathrm{C}_{\mathrm{v}}\right)$ can be calculated from the input parameters using the expression given by Davis and Poulos (1968) as,

$$
\mathrm{c}_{\mathrm{v}}=\frac{\mathrm{kE}}{\gamma_{\mathrm{w}}} \frac{(1-v)}{(1-2 v)(1+v)}
$$

The value of Poisson's ratio of soil affects its consolidation response, but the effect is limited over the range of 0.1 to 0.3 (Booker and Small, 1986). Hence a mid-range value, $v=0.2$, was assigned to the soil, resulting in $\mathrm{c}_{\mathrm{v}}=0.56 \mathrm{~mm}^{2} / \mathrm{s}$ or $17.5 \mathrm{~m}^{2} / \mathrm{yr}$.

The soil domain was meshed using rectangular 4-noded elements with $2 \times 2$ integration (CAX4P). Gourvenec and Randolph (2010) investigated the effect of mesh size along the skirt on the initial excess pore pressures generated and dependency of results on the skirt wall thickness, finding that the mesh dependency decreased with decreasing skirt wall thickness. In this study a mesh size equivalent to 0.025 times the foundation diameter was used for the soil elements near the skirt wall. As the skirt wall thickness used here was very small relative to the diameter $\left(t_{w} / D=0.008\right)$, the effect of mesh density on the results was minimal.

\subsection{Water elements}

Two rows of thin poroelastic elements were inserted between the soil plug and the foundation top plate to simulate a layer of trapped water. The elements were assigned isotropic elastic properties with low modulus and zero Poisson's ratio so that they were able to deform with minimal restraint in response to changes in effective stress. The concept behind the approach is that the water elements will not change volume immediately under changes in total stress, but will instead give rise to excess pore 
pressure within the elements. Volume changes can occur gradually with time due to flow of water from the soil plug into the elements. However, provided the element modulus is sufficiently low, the excess pore pressure (negative in the present study) will be sustained with minimal change as the element expands and thus gives rise to displacement of the foundation.

A parametric study was conducted to choose suitable parameters for the water elements. The study considered a pullout load per unit area (q) of $100 \mathrm{kPa}$ on a foundation with embedment ratio of $d / D=0.2$. From the analyses, it was found that there was negligible effect of parameters such as void ratio, permeability, Poisson's ratio and mesh density of the water elements on the rate of displacement of the foundation due to seepage (see Table 1 for values adopted). The only parameter that affected the foundation response was the modulus of elasticity, $E_{w}$, with values in the range 0.001 to $1 \mathrm{kPa}$ being explored.

Fig. 3 shows the time history of excess pore pressure dissipation at the centreline of the foundation along the underside of the foundation top plate, and the timedependent displacement, wt. Fig. 3(a) compares pore pressure dissipation beneath the foundation for water elements of different elastic modulus and with no water elements. For the 'no water' case the same mesh was used but with the water elements assigned the same properties as the soil $\left(E_{\mathrm{w}}=5000 \mathrm{kPa}\right)$. It can be observed that for all the foundations with water elements, initial negative pore pressure approximately equivalent to the applied uplift pressure was generated, but augmented by $\left(\mathrm{D} / \mathrm{D}_{\mathrm{i}}\right)^{2}$ where $D_{i}$ is the internal diameter of the foundation top plate between the skirts. By contrast the 'no water' case gave initial negative pore pressure of only around $85 \%$ of the applied pressure along the centreline of the foundation. This is because of the non- 
uniform distribution of negative pore pressure beneath the top plate for the 'no water' case, as explained and shown later.

The higher the value of $E_{w}$, the earlier the time at which the negative excess pore pressure started to dissipate, for example at a non-dimensional time $\mathrm{T}=\mathrm{c}_{\mathrm{v}} \mathrm{t} / \mathrm{D}^{2}$ of about 0.02 for the 'no water' case $\left(E_{\mathrm{w}}=5000 \mathrm{kPa}\right)$ compared with $\mathrm{T} \sim 100$ for $E_{\mathrm{w}}=0.01 \mathrm{kPa}$. The reduction in negative pressure occurs as the water layer stretches, and thus transfers stress from the pore fluid to the soil matrix. For example, at a nondimensional time of $\mathrm{T}=10$, corresponding here to around 82 years, the foundation displacement is $\mathrm{w}_{\mathrm{t}} \gamma_{\mathrm{w}} / \mathrm{q} \sim 0.4$, corresponding to $\mathrm{w}_{\mathrm{t}}=4 \mathrm{~m}(0.33 \mathrm{D})$ (see Fig. 3(b)). Since the water layer is $0.1 \mathrm{~m}$ thick $(0.0083 \mathrm{D})$, the engineering strain is 40 , resulting in a vertical effective stress of $40 \mathrm{kPa}$ for $\mathrm{E}_{\mathrm{w}}=1 \mathrm{kPa}$. This is consistent with the reduction in negative pore pressure shown in Fig. 3(a) for that value of $E_{w}$.

Since the intention of the present study was to quantify the foundation displacements resulting from seepage into the skirt compartment, it was important that constant negative pore pressure should be maintained under the top plate for the period of time studied. For the two lowest $E_{\mathrm{w}}$ values of 0.001 and $0.01 \mathrm{kPa}$, the negative pore pressures were sustained fully until $\mathrm{T} \sim 100$, corresponding to several centuries for the particular foundation geometry and soil properties selected.

Fig. 3(b) shows the normalised time-displacement plots for the different values of $E_{w}$ considered in the parametric study. It can be seen that for foundation displacements up to $\mathrm{T}=10$ (corresponding to 82 years here), the rate of displacement due to seepage are of approximately similar magnitudes for $E_{\mathrm{w}}=0.001,0.01$ and $0.1 \mathrm{kPa}$. The choice of $E_{w}$ will depend on the time period of interest; a value of $0.01 \mathrm{kPa}$ was chosen for the remaining results in this study. 
The lower value of initial excess pore pressure observed for the 'no water' case can be explained by considering the pore pressure distribution beneath the foundation top plate immediately after loading. Fig. 4 shows the distribution of initial negative excess pore pressure $\left(\Delta u_{i}\right)$ beneath the foundation top plate (with $\left.d / D=0.2\right)$ for $E_{w}$ values of 0.01 and $5000 \mathrm{kPa}$ (no water) immediately after the application of load. For the case with 'no water', the magnitude of negative pore pressure is highest near the periphery close to the skirt wall $\left(\Delta \mathrm{u}_{\mathrm{i}} / \mathrm{q}=1.18\right)$ and lowest at the centre of the plate $\left(\Delta \mathrm{u}_{\mathrm{i}} / \mathrm{q}=0.85\right.$, as shown in Fig. 3(a)). Incorporation of soft water elements leads to a uniform distribution of negative pore pressure beneath the top plate with magnitude corresponding to the applied pressure, augmented by $\left(D / D_{i}\right)^{2}$ where $D_{i}$ is the internal diameter of the foundation top plate between the skirts.

\section{Results}

Using the selected parameters for the water elements, analyses were conducted on foundations with $\mathrm{d} / \mathrm{D}=0.1,0.2,0.3,0.5$ and 1 , with intact and gapped skirt-soil interfaces. From the analyses, the time-displacement responses of the foundation were obtained and it was also confirmed that minimal pore pressure dissipation occurred beneath the foundation top plate.

\subsection{Foundation displacements}

Fig. 5(a) shows the excess pore pressure dissipation along the centreline beneath the foundation top plate for all the foundations with intact skirt-soil interface. It can be seen that, for the model parameters chosen, constant negative excess pore pressure was maintained for a considerable period of time ( $\mathrm{T}>10$, or 82 years) for all cases.

Fig. 5(b) shows the time-dependent displacements of the foundations with intact skirtsoil interface subjected to uniform vertical uplift pressure q. The (immediate) 
displacements during loading have been subtracted and those shown are only due to swelling of the soil and seepage of water towards the foundation top plate. The timedisplacement relationship becomes linear after an initial period. The initial non-linear response is dominated by foundation displacement due to swelling of the soil while the subsequent linear portion, which continues up to normalised times $\mathrm{T}$ in excess of 10, represents continuing foundation displacement due to seepage of water into the region below the top plate.

Fig. 6(a) compares the foundation displacements due to swelling and seepage with those due to swelling alone (from analyses without 'water' elements). It can be seen that for the shallowest skirt $(\mathrm{d} / \mathrm{D}=0.1)$ the foundation displacement at $\mathrm{T}=1.2$ (approximately 10 years) due to swelling alone accounts for only about $10 \%$ of that when seepage is included. Fig. 6(b) shows the initial portion of the responses for a single case $(d / D=0.3)$, with and without water elements. In both cases, a similar trend of displacements is observed initially. Hence it is apparent that the initial nonlinear portion of the curve in Fig. 6 is due to swelling of the soil inside and beneath the skirt compartment. Once seepage has been established, the displacement increases linearly with time, with the rate of displacement determined by the seepage velocity of water towards the foundation top plate.

Fig. 7 compares the steady state displacement rates for foundations with an intact skirt-soil interface with those for foundations with a gapped interface. As expected, the displacement rates are higher for the latter case, due to the free water drawn directly into the skirt compartment from the gap at skirt tip level. 


\subsection{Seepage length}

The displacements during the linear portion of the time-displacement curves (in Fig. 7) arise solely from seepage of water towards the top plate such that the displacement rates are equivalent to the average seepage velocity of water at the top of the soil plug. Fig. 8 shows normalised seepage velocities for all the foundations studied with intact and gapped skirt-soil interfaces.

From Darcy’s law, the seepage velocity may be expressed as

$$
\mathrm{v}=\mathrm{k} \times \mathrm{i}
$$

where $\mathrm{i}$ is the hydraulic gradient, which is a function of the applied load per unit area (q), unit weight of pore water $\left(\gamma_{\mathrm{w}}\right)$ and seepage length (s):

$$
\mathrm{i}=\frac{\mathrm{q}}{\mathrm{s} \gamma_{\mathrm{w}}}
$$

Thus,

$$
\mathrm{v}=\frac{\Delta \mathrm{w}_{\mathrm{t}}}{\Delta \mathrm{t}}=\mathrm{ki}=\mathrm{k} \frac{\mathrm{q}}{\mathrm{s} \gamma_{\mathrm{w}}}=\frac{\mathrm{kq}}{\gamma_{\mathrm{w}} \mathrm{D}} \frac{\mathrm{D}}{\mathrm{s}}
$$

From the seepage velocities obtained from the finite element analyses (Fig. 8), the seepage length can be calculated using the relationship (adjusting for the slightly greater excess pore pressure of $\Delta \mathrm{u} / \mathrm{q}=1.03)$ :

$$
\frac{\mathrm{s}}{\mathrm{D}}=\frac{\mathrm{k} \Delta \mathrm{u}}{\gamma_{\mathrm{w}} \mathrm{D}}\left(\frac{\Delta \mathrm{w}_{\mathrm{t}}}{\Delta \mathrm{t}}\right)^{-1}
$$

Fig. 9 shows the normalised seepage lengths, s/D, calculated using equation (6) for foundations with intact and gapped skirt-soil interfaces, for the range of embedment ratios studied.

Previous studies have reported equivalent seepage lengths for suction caissons with different embedment ratios in sand, although the main focus has been on the 
maximum hydraulic gradient (so minimum seepage length) adjacent to the skirt wall (Erbrich and Tjelta, 1999; Houlsby and Byrne, 2005; Senders and Randolph, 2009). Senders and Randolph (2009) also gave an expression to calculate the average seepage length as a function of the foundation embedment ratio:

$$
\frac{\mathrm{s}}{\mathrm{d}}=1+0.2\left(\frac{\mathrm{d}}{\mathrm{D}}\right)^{-0.9}
$$

Slightly improved fits to the seepage lengths calculated from this study were obtained through minor adjustments to the constants in equation (7). Seepage lengths from this study shown in Fig. 9 can be generally expressed as:

$$
\frac{\mathrm{s}}{\mathrm{D}}=\frac{\mathrm{d}}{\mathrm{D}} \min \left(\mathrm{A}, 1+\mathrm{B}\left(\frac{\mathrm{d}}{\mathrm{D}}\right)^{-\mathrm{C}}\right)
$$

where $(A, B, C)=(\pi, 0.22,1)$ and $(\pi, 0.14,1)$ for the intact and gapped skirt-soil interfaces respectively for the best fits with the numerical data. The upper limit of normalised seepage length (constant A) for the best fits is equal to $\pi$, which is also the theoretical value of normalised seepage length for sheet pile wall with very low embedment ratios (Bruggeman, 1999). For very high embedment ratios, the seepage length tends to be equal to the skirt length, as the hydraulic head loss essentially occurs inside the skirt compartment. The seepage lengths calculated using equation (7), normalised as s/D, are also plotted in Fig. 9 for comparison.

\subsection{Comparison with centrifuge results}

In order to validate the applicability of this study, the numerical results have been compared with available results from centrifuge model tests. Drum centrifuge tests were conducted on a skirted foundation model with embedment ratio $d / D=0.2$ with 
the same prototype diameter and skirt wall thickness at $200 \mathrm{~g}$ as in the finite element study, in a lightly over consolidated clay sample. The details of the drum centrifuge, foundation model, soil sample, test set up and test procedure are described by Mana et al. (2012). Initially a displacement controlled undrained uplift test was conducted and the ultimate undrained uplift capacity of the foundation, expressed as the average uplift pressure, $\mathrm{q}_{\mathrm{u}}$, was obtained. Subsequently, load controlled tests equivalent to sustained average uplift pressures (q) of 10, 20, 40 and $60 \%$ of the ultimate uplift capacity were performed.

Fig. 10(a) and (b) show respectively the time-displacement profiles during the sustained load tests on foundations with intact and gapped skirt-soil interfaces in the centrifuge. The displacements due to swelling and seepage of water into the skirt compartment are plotted, i.e. after first subtracting the immediate elastic displacement from the total displacement of the foundation. The time-displacement behaviour follows a quasi-linear trend in all cases, with the gradients indicating the rate of flow of water into the skirt compartment.

The seepage velocities from the centrifuge tests, calculated from Fig. 10, are plotted against the respective normalised loads in Fig. 11. The results are compared with the seepage velocities predicted using equations (5) and (8) with a back-calculated value of $\mathrm{k}=2 \times 10^{-9} \mathrm{~m} / \mathrm{s}$ and assigning the loads applied in the centrifuge tests. The assumed value of $\mathrm{k}$ corresponds to the coefficient of permeability that gives best prediction of the seepage velocities from centrifuge tests. The kaolin clay used in the centrifuge sample has an expected coefficient of permeability in this range, between $1.1 \times 10^{-10} \mathrm{~m} / \mathrm{s}$ and $5.1 \times 10^{-9} \mathrm{~m} / \mathrm{s}$ (Acosta-Martinez and Gourvenec, 2006). 
It can be seen that the seepage velocities using the equations derived from FEA are consistent with those from the centrifuge tests at low loads ( $q / q_{u}$ less than about 0.2 ), but the experimental seepage velocities are much higher at high load ratios. This is due to the non-linear behaviour of real soil, so that at high load ratios the displacement response becomes increasingly dominated by the non-linear and timedependent response of the soil around the foundation (e.g. due to creep), rather than seepage into the skirt compartment. Note that for the lower load levels where the rate of movement is well predicted from the seepage analysis, the cumulative foundation displacements are less than about $1 \%$ of the foundation width, so that strains within the soil are small apart from locally close to the skirt tips.

\subsection{Design considerations}

There are some caveats on using the results from this finite element study in design practice. In particular:

- $\quad$ The assumption of elastic properties for the soil ignores the non-linear and strain rate-dependent nature of real soil. The results appear applicable for loads equivalent to low proportions (less than about $20 \%$ ) of the ultimate load capacity of the foundation.

- In the finite element study, it was assumed that soil inside the skirt was fully bonded to the top plate and that suction was maintained beneath the top plate throughout the analysis. In reality suction would be lost once the cumulative displacement reached a significant proportion of the skirt depth (depending on how much soil is dragged down adjacent to the skirts).

- $\quad$ The skirt walls were assumed to be fully smooth in all the analyses. The effect of interface friction down the skirts would be to reduce the ratio of excess pore 
pressure to the applied uplift pressure, and hence reduce the magnitude of timedependent displacements.

- Uniform, time-independent, isotropic properties were assumed for the soil in the analyses. Application of the results therefore need to consider the average permeability of the soil in the zone of interest, particularly within the soil plug, and any changes that might occur due to swelling of the soil.

\section{Conclusions}

A numerical technique has been presented for simulating the time-dependent displacement response of skirted foundations loaded in uplift, using small strain finite element analysis. The study considered isotropic elastic properties for the soil, with the main focus being on steady state seepage into the skirt compartment, and the balance between displacements resulting from swelling of the soil and those from seepage. The analyses led to refinement of previously published expressions for estimating the average seepage path length as a function of the foundation embedment ratios, also evaluating the influence of a physical gap down the external skirts. For a given seepage path length it is then straightforward to evaluate the steady state rate of foundation displacement as a function of the permeability of the soil and the applied loading. The results showed good agreement with results from centrifuge model tests for low to moderate load levels relative to the ultimate uplift capacity.

\section{Acknowledgements}

The work described in this paper forms part of the activities of the Centre for Offshore Foundation Systems, currently supported as a node of the Australian Research Council Centre of Excellence for Geotechnical Science and Engineering, and in partnership with The Lloyd's Register Foundation. Support through the 
Australian Research Council’s Discovery Program is also acknowledged, in particular through ARC grant DP0988904.

\section{References}

Acosta-Martinez HE, Gourvenec SM. One-dimensional consolidation tests on kaolin clay. Report Research Report GEO: 06385 2006. Centre for Offshore Foundations Systems, School of Civil and Resource Engineering, The University of Western Australia.

Acosta-Martinez HE, Gourvenec SM, Randolph MF. An experimental investigation of a shallow skirted foundation under compression and tension. Soils and Foundations 2008; 48(2): 247-254.

Acosta-Martinez HE, Gourvenec SM, Randolph MF. Effect of gapping on the transient and sustained uplift capacity of a skirted foundation in clay. Soils and Foundations 2010 50(5): 725-735.

Al-Khafaji Z, Audibert JME, Hossain MK, Templeton JS, Clukey EC, de Jong, PR. Suction caisson foundation design for vortex-induced vibration loading. Proc., Offshore Technology Conf., Houston; 2003: OTC 15239.

Biot MA. Le problème de la consolidation des matières argileuses sous une charge. Annaies de la Societe Scientific de Bruxelles B55; 1935. p. 110-3.

Biot MA. General theory of three-dimensional consolidation. J. Appl. Phys. 1941; 12(2): 155-64.

Booker JR, Small JC. The behaviour of an impermeable flexible raft on a deep layer of consolidating soil. Int. J. Numer. Analyt. Meth. Geomech. 1986; 10(3): 311-27.

Bruggeman GA. Analytical solutions of geohydrological problems. New York: Elsevier; 1999.

Cao J, Phillips R, Popescu R, Audibert, JME, Al-Khafaji Z. Proc. $12^{\text {th }}$ Int. Offshore \& Polar Engng. Conf., Kitakyushu, Japan; 2002. p. 795-799.

Clukey EC, Templeton JS, Randolph MF, Phillips R. Suction caisson response under sustained loop current loads. Proc., Offshore Technology Conf., Houston; 2004: OTC 16843.

Dassault Systèmes. Abaqus analysis users’ manual. Providence, RI, USA: Simula Corp; 2010.

Davis EH, Poulos HG. The use of elastic theory for settlement prediction under threedimensional conditions. Géotechnique 1968; 18(1): 67-91.

Deng W, Carter JP. A theoretical study of the vertical uplift capacity of suction caissons. Int. J. Offshore \& Polar Engng. 2002; 12(2): 89-97. 
Erbrich CT, Tjelta TI. Installation of bucket foundations and suction caissons in sand - Geotechnical performance. Proc., Offshore Technology Conf., Houston; 1999: OTC 10990.

Gourvenec SM, Randolph MF. Effect of foundation embedment on consolidation response. Proc. 17 ${ }^{\text {th }}$ Int. Conf. Soil Mech. Geotech. Engng., Alexandria; 2009. p. 638-41.

Gourvenec S, Randolph MF. Consolidation beneath circular skirted foundations. Int. J. Geomech., ASCE 2010; 10(1): 22-9.

Houlsby GT, Byrne BW. Calculation procedures for installation of suction caissons in sand. Geotech. Eng. 2005; 158: 135- 44.

Mana DSK, Gourvenec SM, Randolph MF, Hossain MS. Effect of gapping on the uplift resistance of a shallow skirted foundation. Proc. $7^{\text {th }}$ Int. Offshore Site Inv. \& Geotech. Conf., Society of Underwater Technology, London; 2012. p. 403-10

Senders M, Randolph MF. CPT-based method for the installation of suction caissons in sand. J. Geotech. \& Geoenv. Engng., ASCE 2009; 135(1): 14-25.

Vermeer PA, Verruijt A. An accuracy condition for consolidation by finite elements. Int. J. Num. Analyt. Meth. Geomech. 1981; 5(1): 1-14.

Zdravkovic L, Potts DM, Jardine RJ. A parametric study of the pull-out capacity of bucket foundations in soft clay. Géotechnique 2001; 51(1): 55-67. 


\section{TABLES}

Table 1 Parameters used for the study

\begin{tabular}{|c|c|}
\hline Parameters & Values \\
\hline \multicolumn{2}{|l|}{ Foundation: } \\
\hline Foundation diameter, D & $12 \mathrm{~m}$ \\
\hline Skirt embedment ratios, $\mathrm{d} / \mathrm{D}$ & $0.1,0.2,0.3,0.5 \& 1$ \\
\hline Skirt wall thickness, $\mathrm{t}_{\mathrm{w}}$ & $0.1 \mathrm{~m}\left(\mathrm{t}_{\mathrm{w}} / \mathrm{D}=0.008\right)$ \\
\hline Inner skirt wall-soil interface & $\begin{array}{l}\text { Fully smooth, Hard normal } \\
\text { contact with no separation } \\
\text { allowed }\end{array}$ \\
\hline $\begin{array}{l}\text { Skirt tip-soil interface \& outer skirt wall- } \\
\text { soil interface }\end{array}$ & $\begin{array}{l}\text { Fully smooth, Hard normal } \\
\text { contact with separation } \\
\text { allowed after contact }\end{array}$ \\
\hline Top plate-water interface & $\begin{array}{l}\text { Fully smooth, Hard normal } \\
\text { contact with no separation } \\
\text { allowed }\end{array}$ \\
\hline Material property & Rigid body \\
\hline \multicolumn{2}{|l|}{ Soil: } \\
\hline Young's modulus, E & $5000 \mathrm{kPa}$ \\
\hline Poisson's ratio, $v$ & 0.2 \\
\hline Coefficient of permeability, $\mathrm{k}$ & $1 \times 10^{-9} \mathrm{~m} / \mathrm{s}$ \\
\hline Void ratio, e & 1.3 \\
\hline Specific weight of water, $\gamma_{w}$ & $10 \mathrm{kN} / \mathrm{m}^{3}$ \\
\hline Soil-water interface & $\begin{array}{l}\text { Fully smooth, Hard normal } \\
\text { contact with no separation } \\
\text { allowed }\end{array}$ \\
\hline \multicolumn{2}{|l|}{ Water: } \\
\hline Element thickness & $0.05 \mathrm{~m}$ \\
\hline Young's modulus, $\mathrm{E}_{\mathrm{w}}$ & $0.01 \mathrm{kPa}$ \\
\hline Poisson's ratio, $v_{\mathrm{w}}$ & 0 \\
\hline Coefficient of permeability, $\mathrm{k}_{\mathrm{w}}$ & $1 \mathrm{~m} / \mathrm{s}$ \\
\hline Void ratio, $\mathrm{e}_{\mathrm{w}}$ & 1.3 \\
\hline
\end{tabular}




\section{FIGURE CAPTIONS}

Fig. 1. Schematic of a skirted foundation subjected to vertical uplift loading

Fig. 2. Finite element mesh used for the study

Fig. 3. Influence of the choice of elastic modulus of water elements on the pore pressure dissipation (along the foundation centreline) and foundation displacement with time $(\mathrm{d} / \mathrm{D}=0.2, \mathrm{q}=100 \mathrm{kPa})$

Fig. 4. Comparison of the initial excess pore pressure distribution beneath the foundation top plate for foundations with and without water elements $(\mathrm{d} / \mathrm{D}=0.2, \mathrm{q}=$ $100 \mathrm{kPa})$

Fig. 5. Time histories of (a) pore pressure dissipation and (b) displacements for foundations with different embedment ratios subjected to a constant uplift load of 100 $\mathrm{kPa}$

Fig. 6. (a) Comparison of the time histories of foundation displacements due to consolidation alone with that due to consolidation and seepage (b) Time-displacement curve for $\mathrm{d} / \mathrm{D}=0.3$ for the initial 1 year period

Fig. 7. Time histories of foundation displacements for intact (solid lines) and gap (dotted lines) cases

Fig. 8. Normalised rate of foundation displacement for different embedment ratios Fig. 9. Normalised seepage lengths calculated from FEA for different embedment ratios

Fig. 10. Time-displacement profiles from centrifuge sustained load tests for foundations with (a) intact and (b) gapped skirt-soil interfaces Fig. 11. Comparison of the normalised rate of foundation displacements under different loads from centrifuge with that using equations derived from FEA (assuming $\mathrm{k}=2 \times 10^{-9} \mathrm{~m} / \mathrm{s}$ ) for foundations with (a) intact and (b) gapped skirt-soil 


\section{FIGURES}

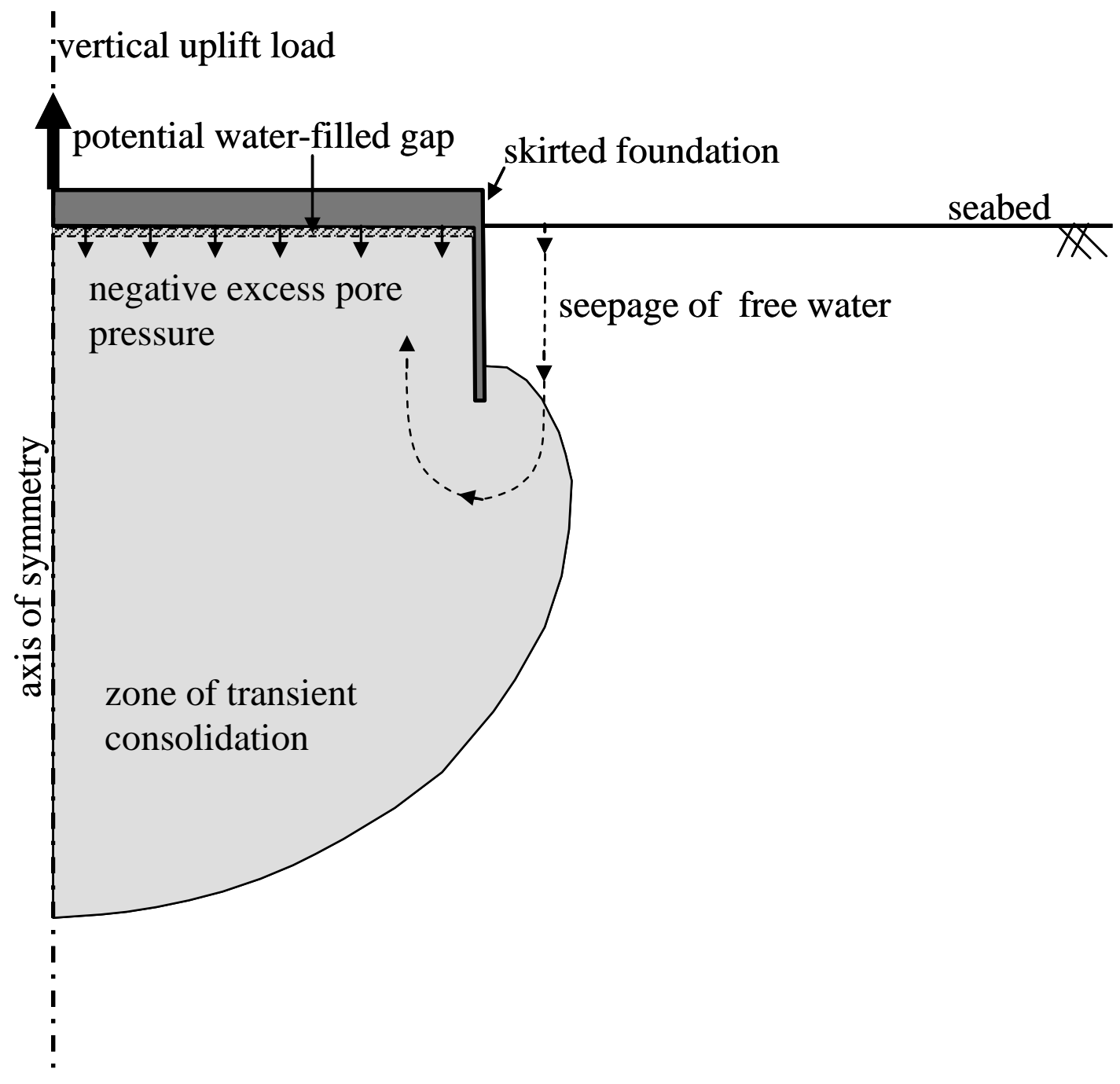

Fig. 1. Schematic of a skirted foundation subjected to vertical uplift loading 


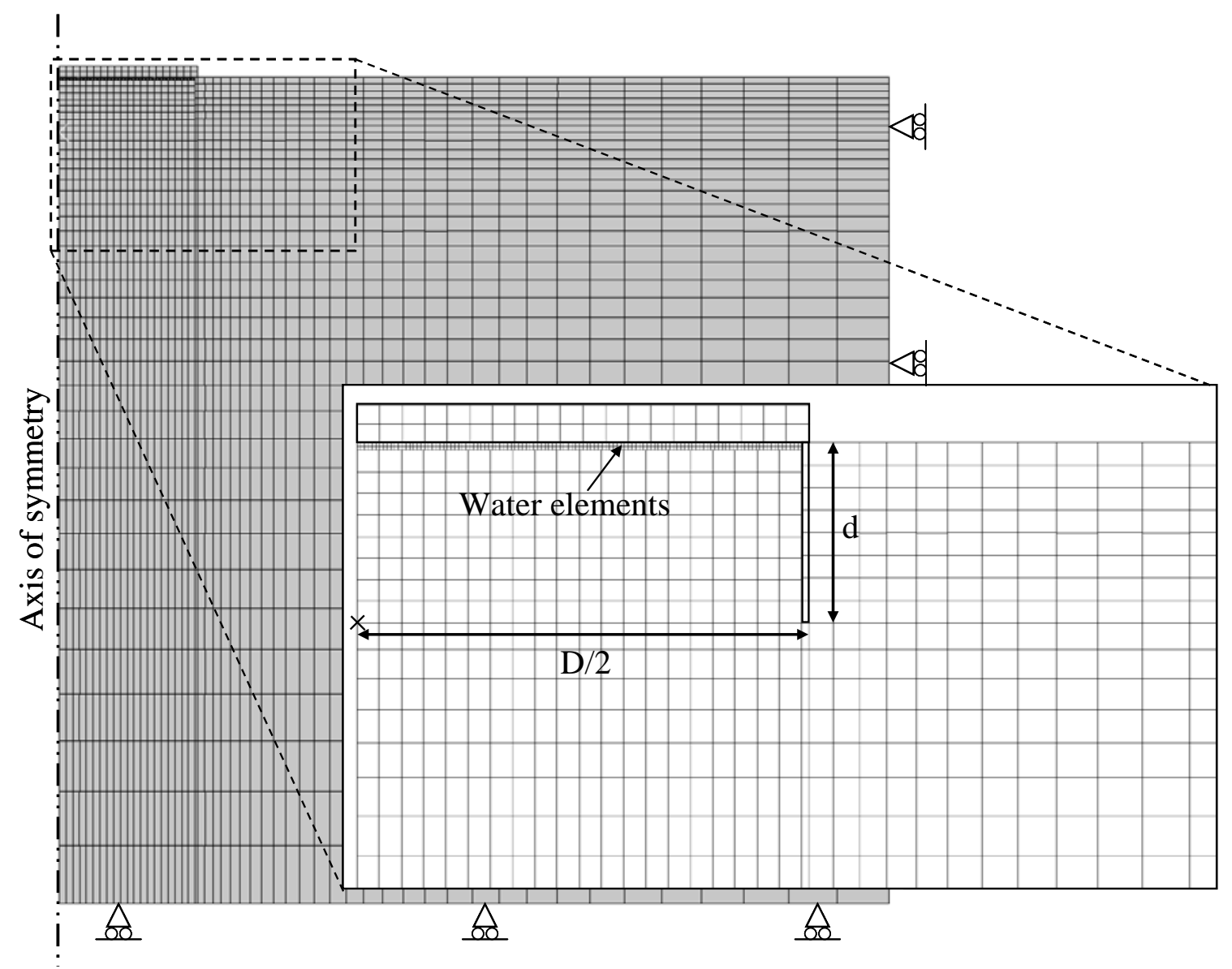

Fig. 2 Finite element mesh used for the study 


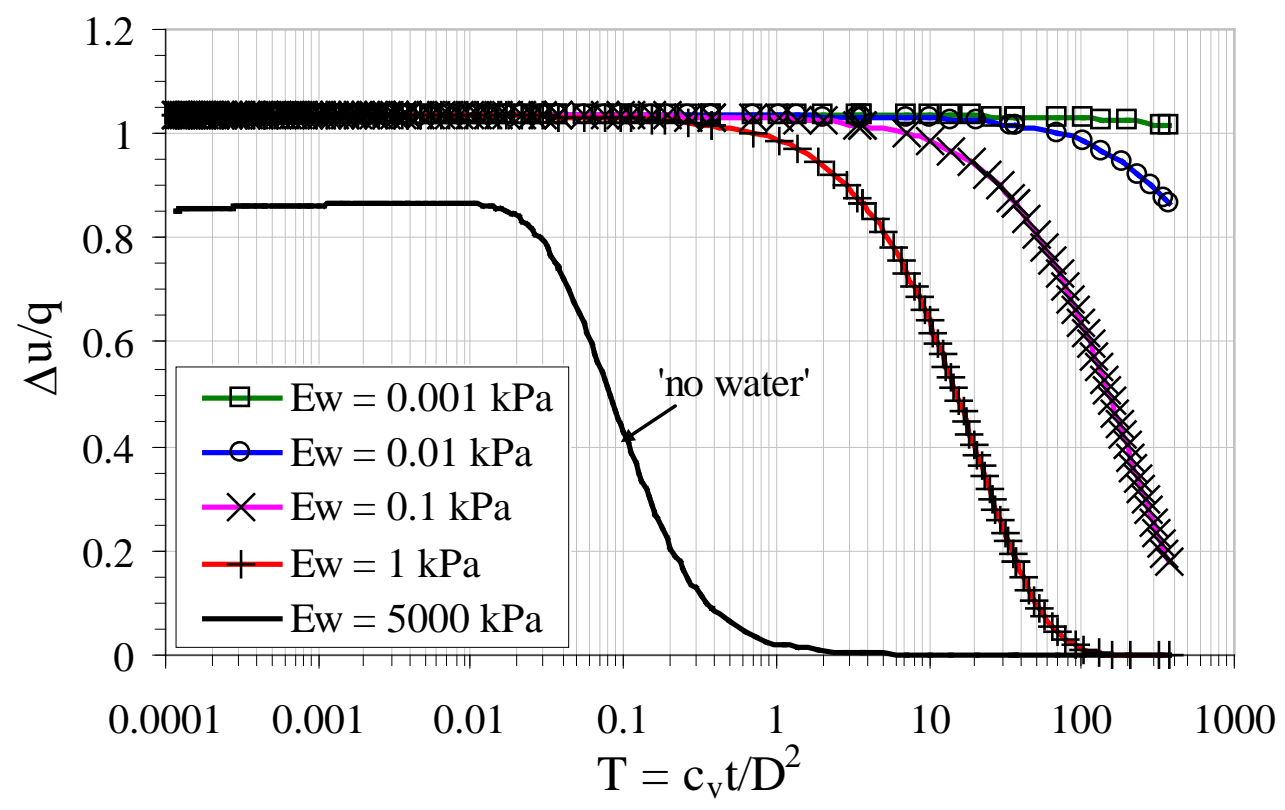

(a)

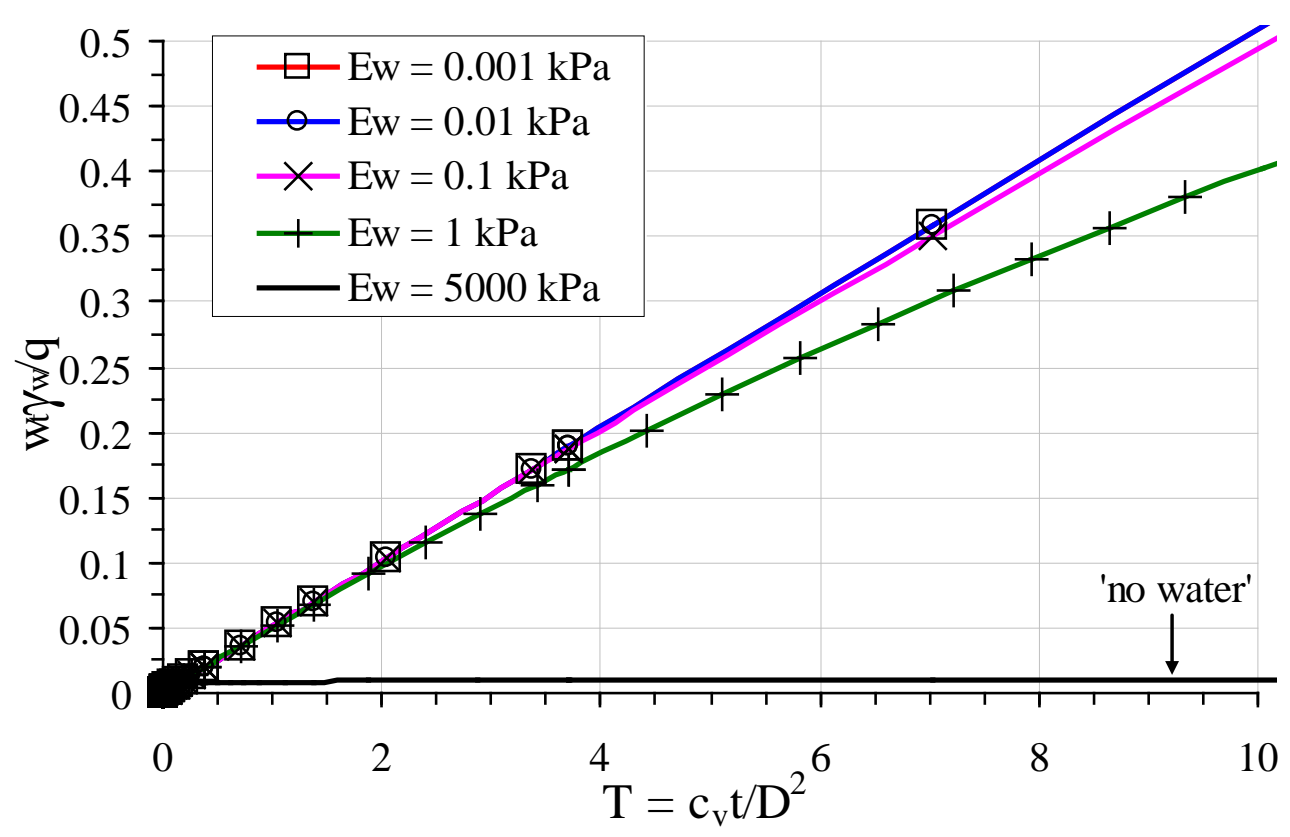

(b)

Fig. 3. Influence of the choice of elastic modulus of water elements on the pore pressure dissipation (along the foundation centreline) and foundation displacement with time $(\mathrm{d} / \mathrm{D}=\mathbf{0 . 2}, \mathrm{q}$ $=100 \mathrm{kPa}$ ) 


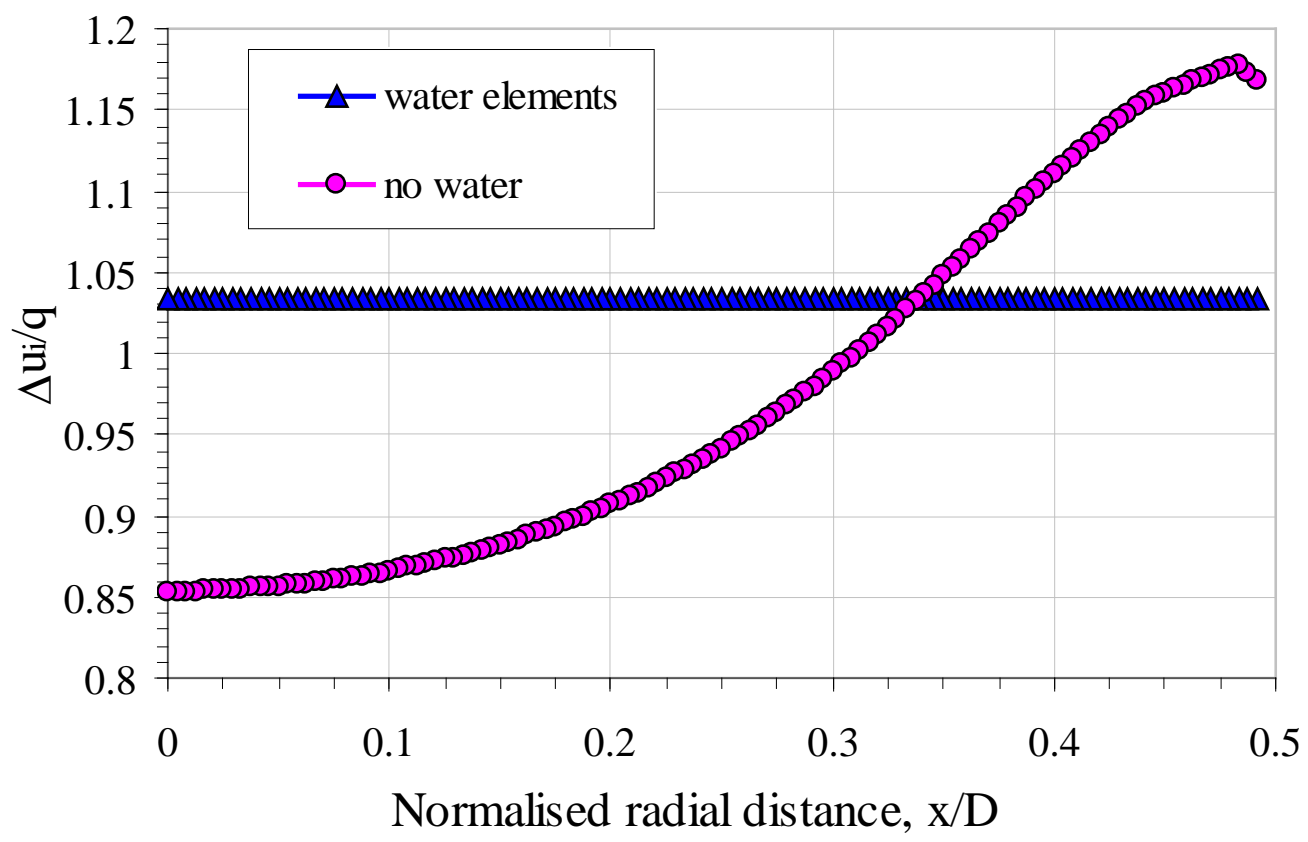

Fig. 4. Comparison of the initial excess pore pressure distribution beneath the foundation top plate for foundations with and without water elements $(\mathrm{d} / \mathrm{D}=0.2, \mathrm{q}=100 \mathrm{kPa})$ 


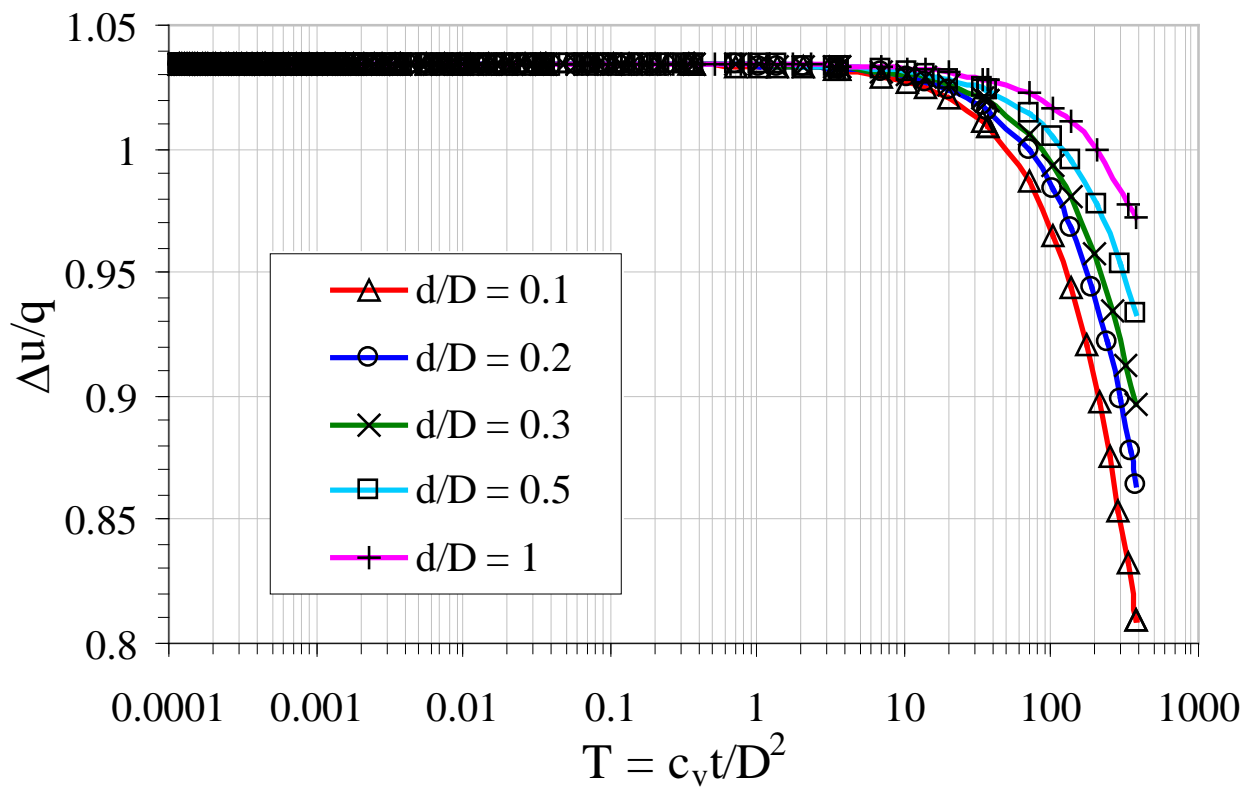

(a)

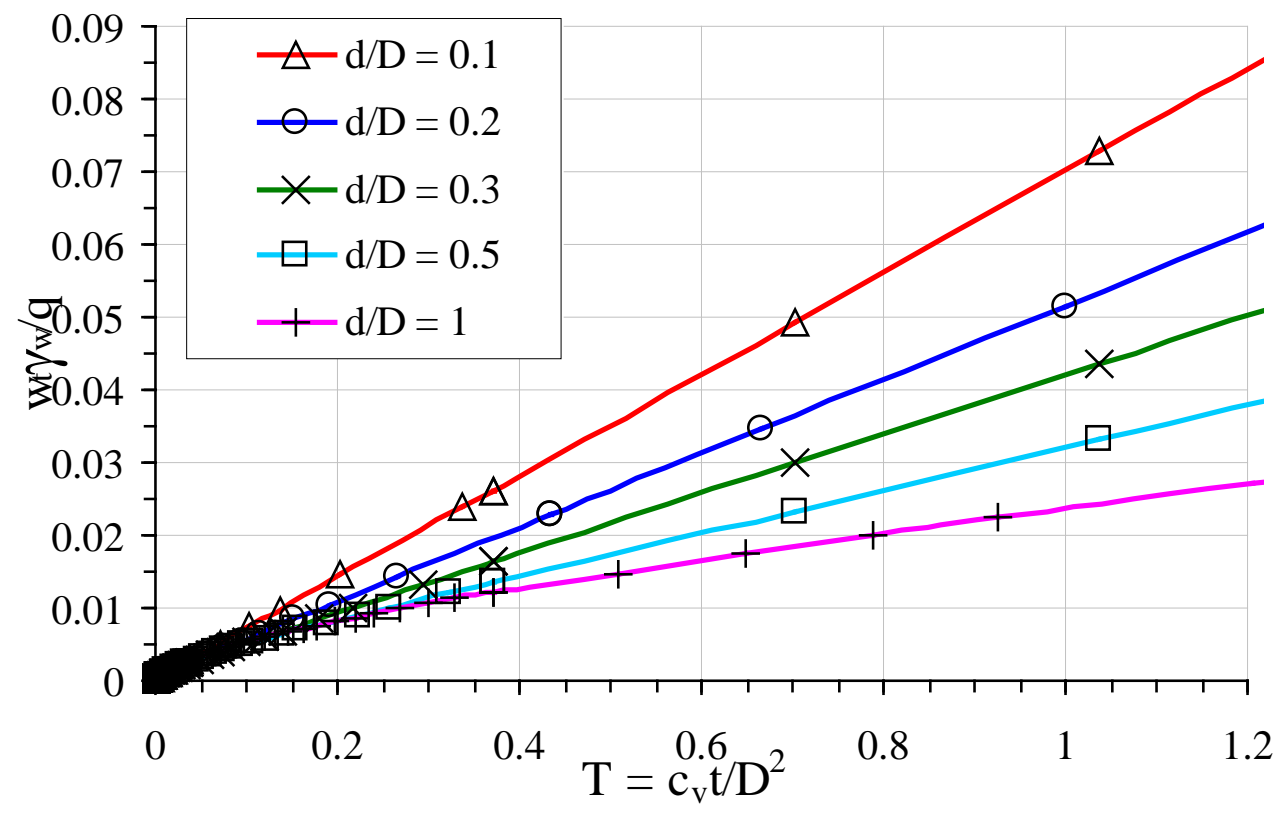

(b)

Fig. 5. Time histories of (a) pore pressure dissipation and (b) displacements for foundations with different embedment ratios subjected to a constant uplift load of $100 \mathrm{kPa}$ 


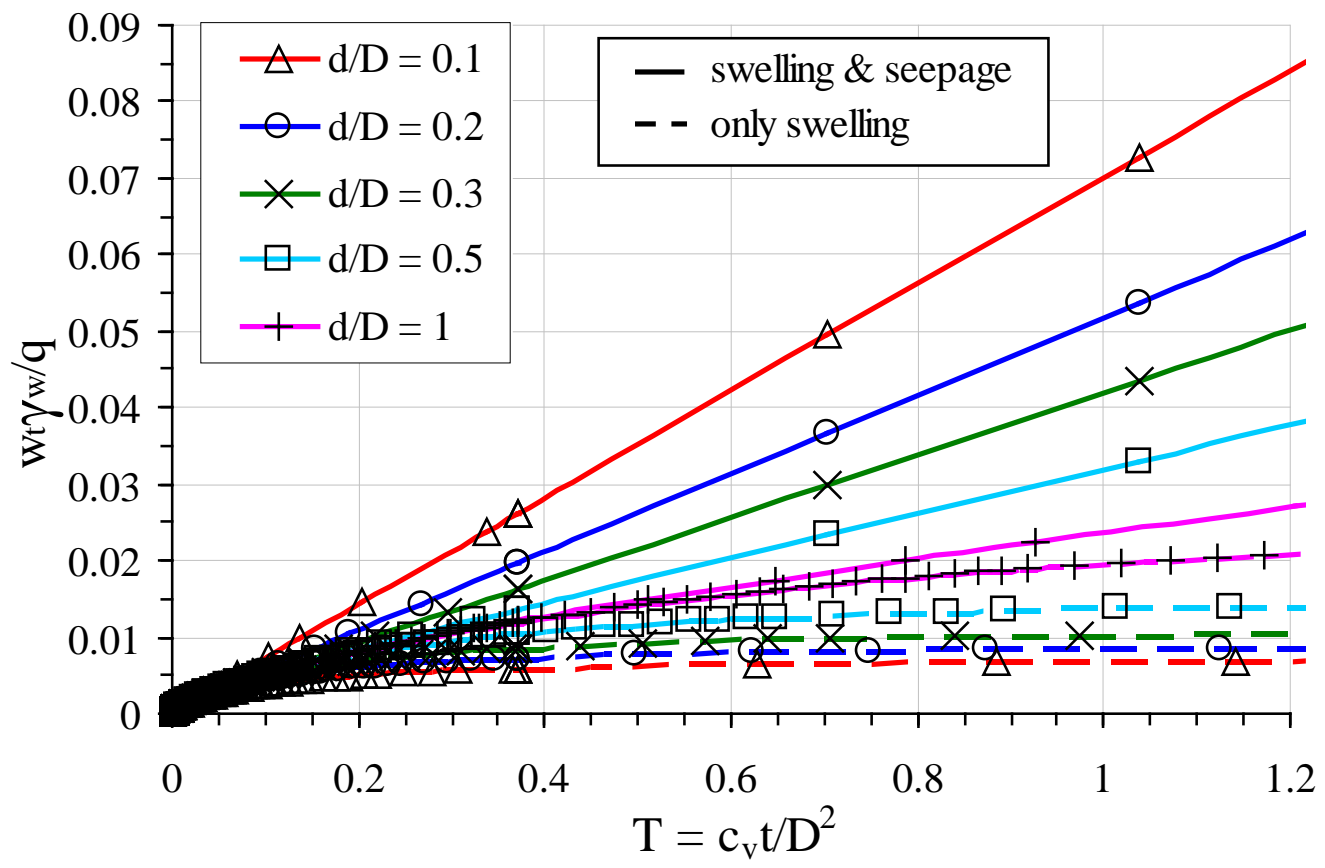

(a)

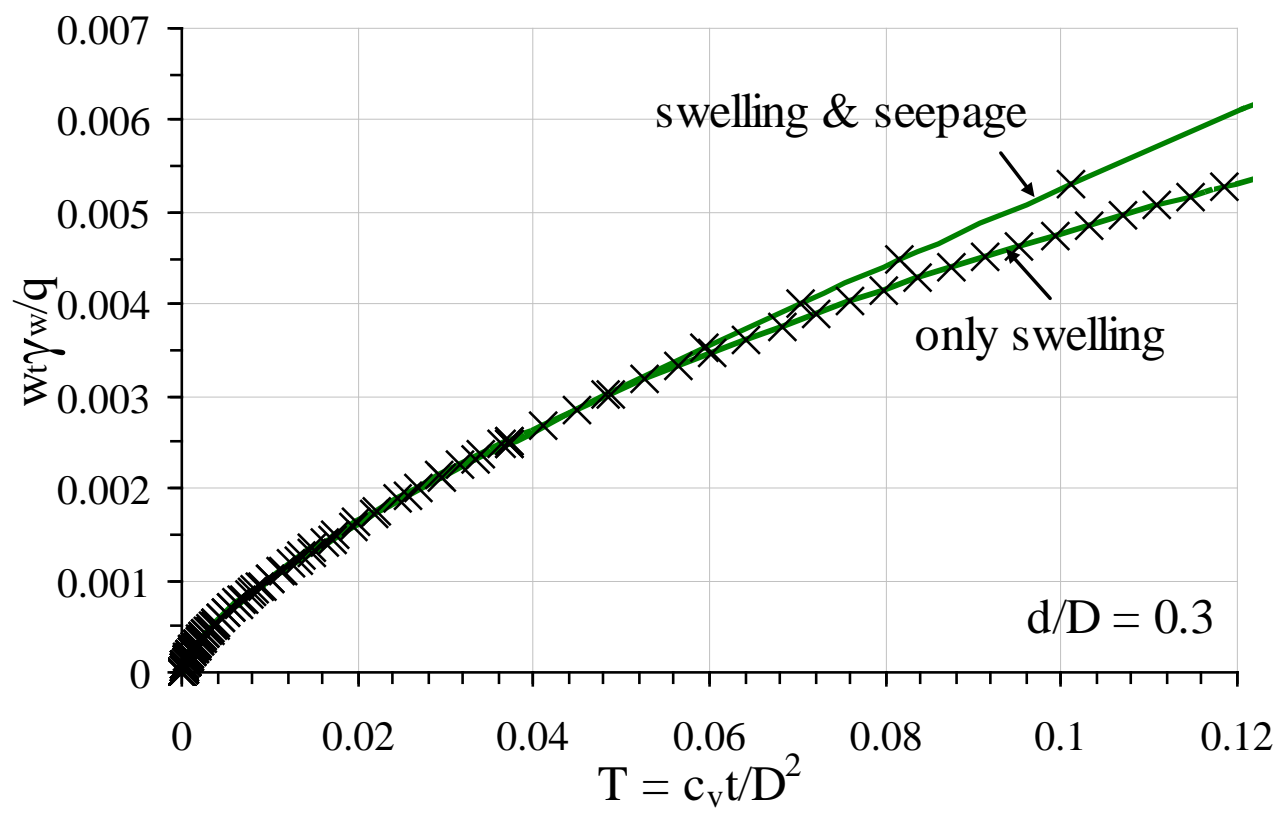

(b)

Fig. 6. (a) Comparison of the time histories of foundation displacements due to consolidation alone with that due to consolidation and seepage (b) Time-displacement curve for $\mathrm{d} / \mathrm{D}=\mathbf{0 . 3}$ for the initial 1 year period 


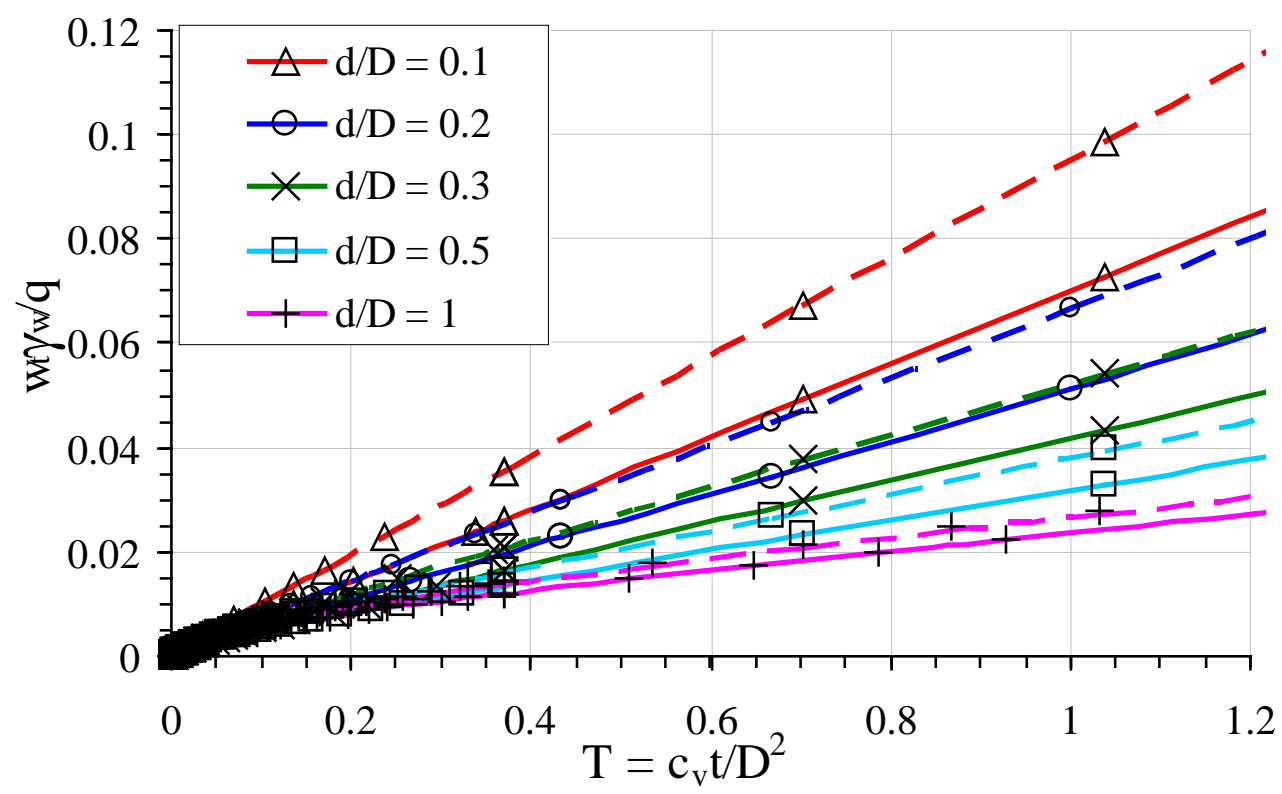

Fig. 7. Time histories of foundation displacements for intact (solid lines) and gap (dotted lines) cases

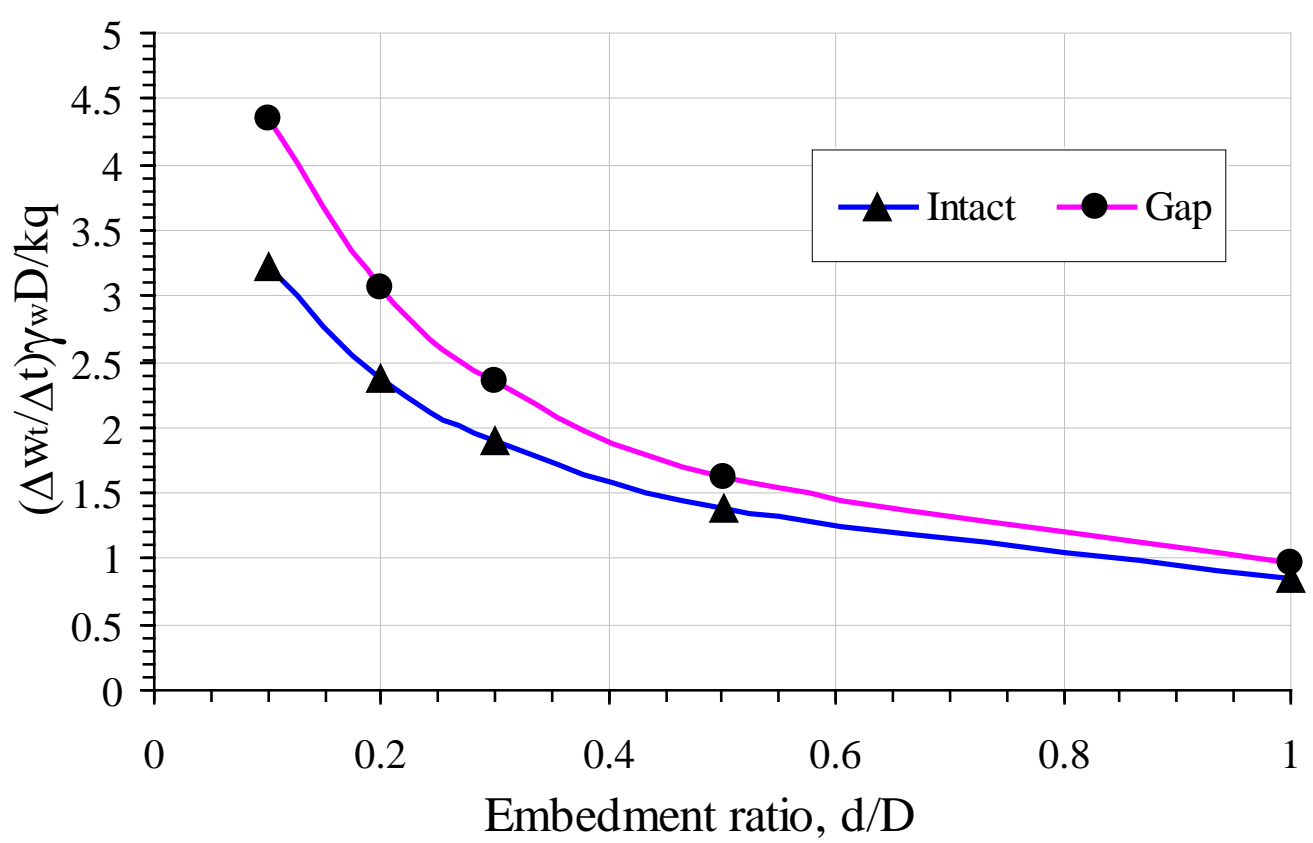

Fig. 8. Normalised rate of foundation displacement for different embedment ratios 


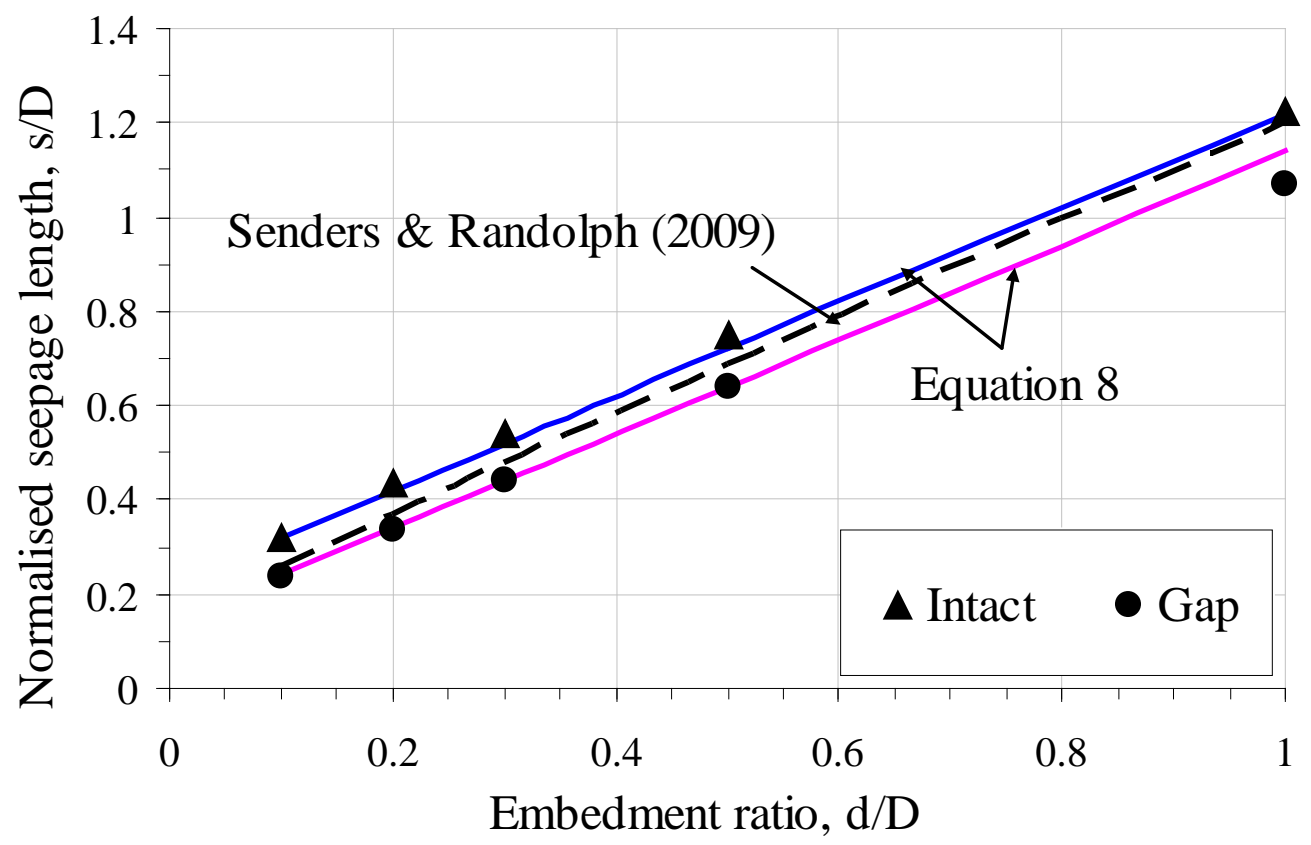

Fig. 9. Normalised seepage lengths calculated from FEA for different embedment ratios 


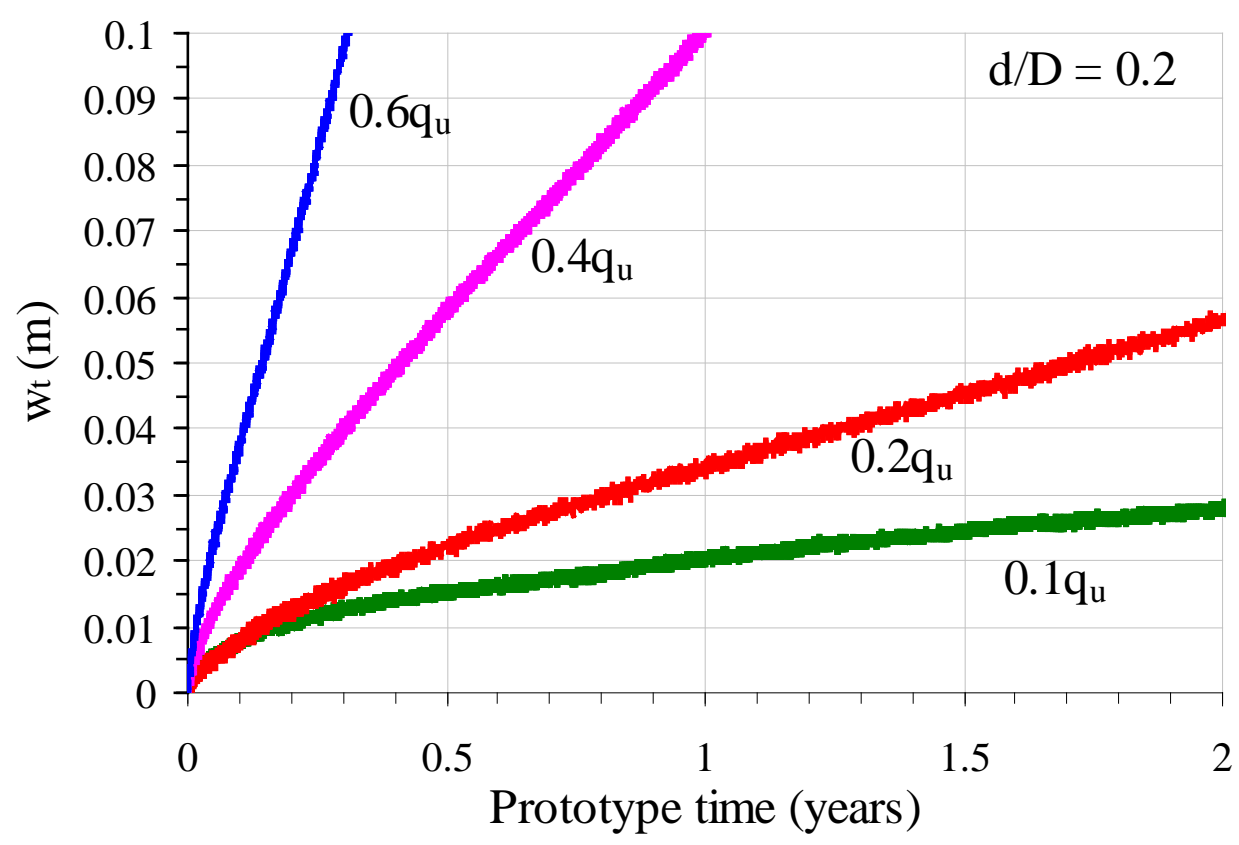

(a)

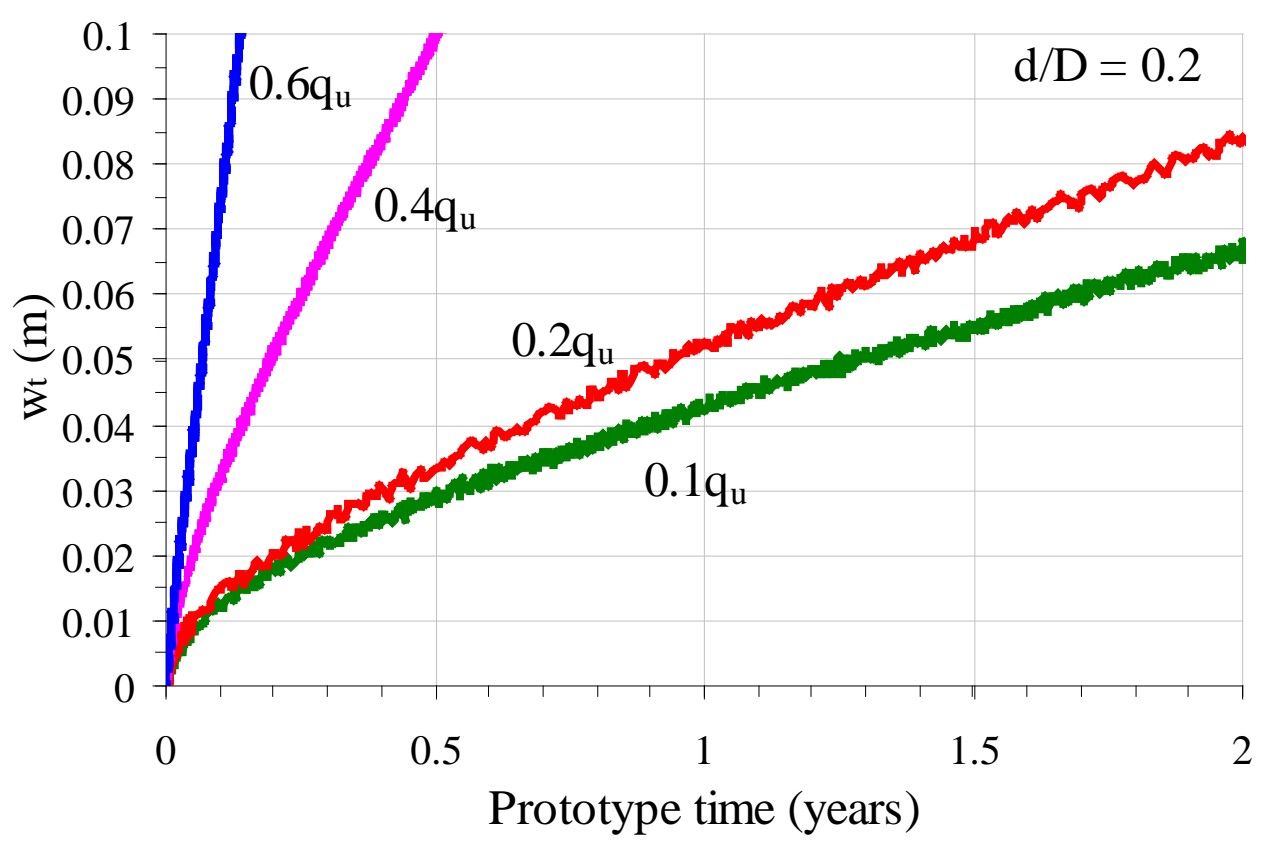

(b)

Fig. 10. Time-displacement profiles from centrifuge sustained load tests for foundations with (a) intact and (b) gapped skirt-soil interfaces 


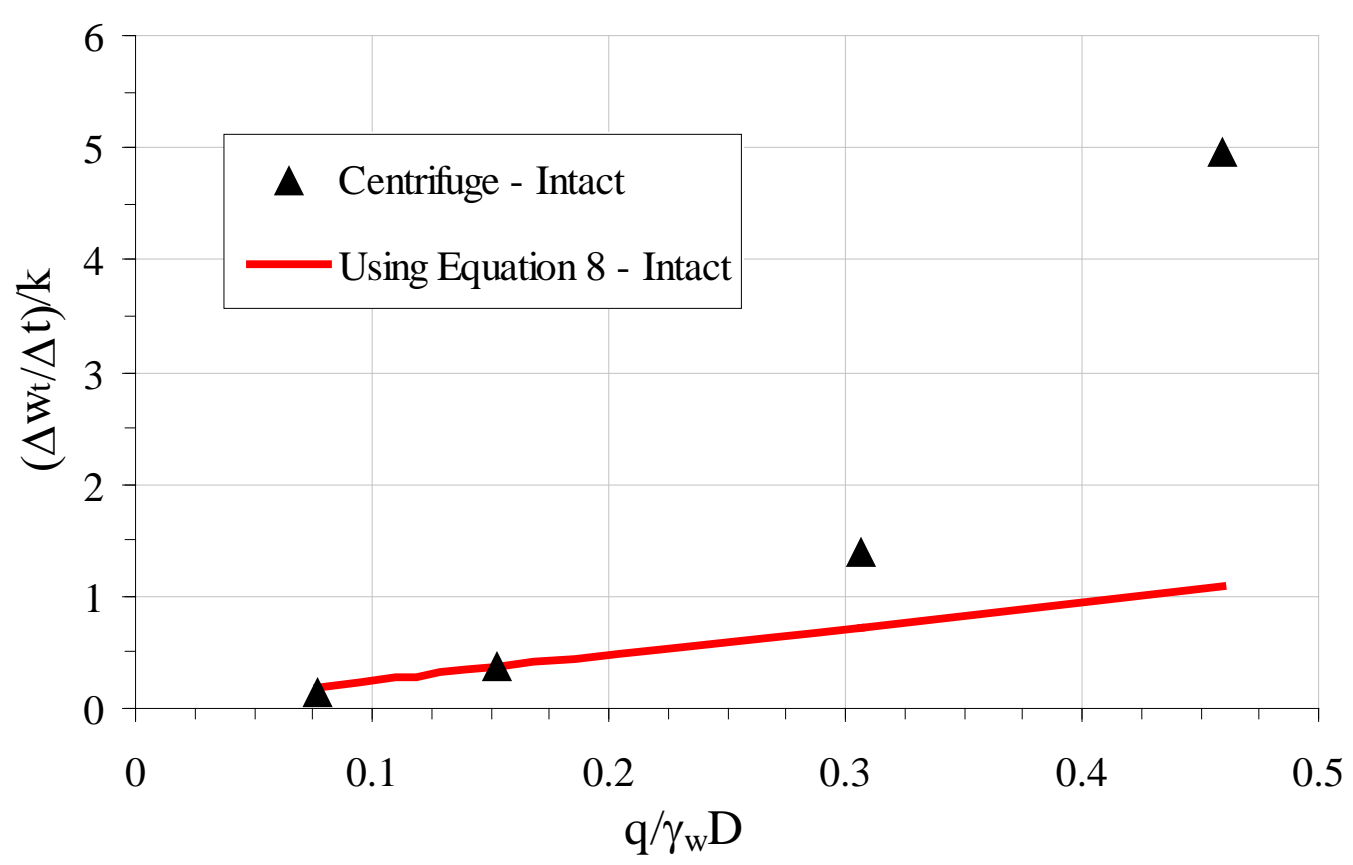

(a)

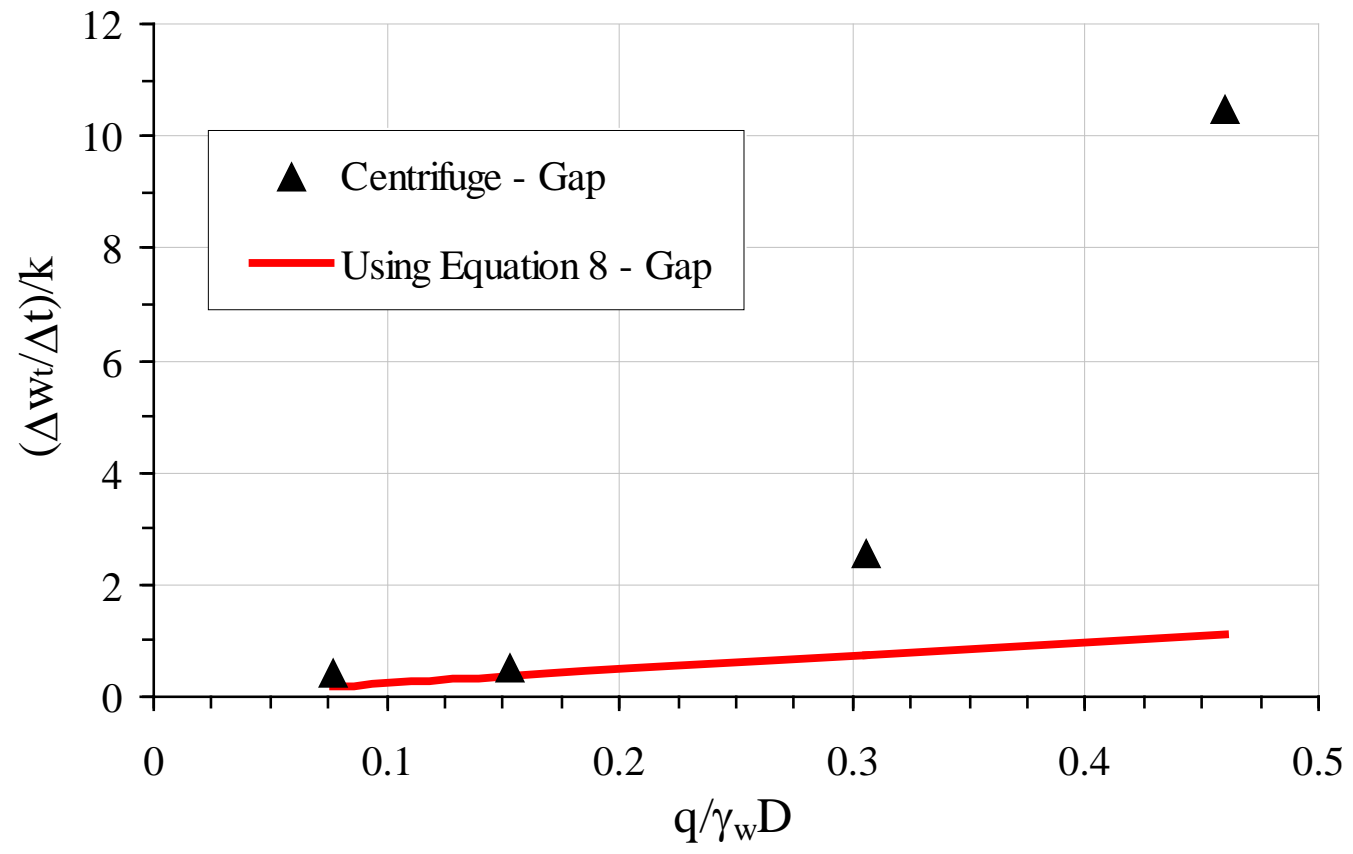

(b)

Fig. 11. Comparison of the normalised rate of foundation displacements under different loads from centrifuge with that using equations derived from FEA (assuming $\mathrm{k}=2 \times 10^{-9} \mathrm{~m} / \mathrm{s}$ ) for foundations with (a) intact and (b) gapped skirt-soil 